\title{
A Systematic Review of Mycoplasma and Ureaplasma in Urogynaecology
}

\section{Mykoplasmen und Ureaplasmen in der Urogynäkologie - ein systematischer Review}

\author{
Authors \\ Nina Combaz(-Söhnchen) ${ }^{1}$, Annette Kuhn ${ }^{2}$ \\ Affiliations \\ 1 Abteilung Frau und Kind, Spital Sitten, Sitten, Schweiz \\ 2 Urogynäkologie Frauenklinik, Inselspital, Bern, Schweiz
}

Key words

mycoplasma, ureaplasma, hyperactive bladder, bladder pain syndrome, infections in urogynaecology

Schlüsselwörter

Mykoplasma, Ureaplasma, hyperaktive Blase, Bladder Pain Syndrome, Infektionen in der Urogynäkologie

$\begin{array}{ll}\text { received } & 1.7 .2017 \\ \text { revised } & 12.9 .2017 \\ \text { accepted } & 13.9 .2017\end{array}$

Bibliography

DOI https://doi.org/10.1055/s-0043-119687

Geburtsh Frauenheilk 2017; 77: 1299-1303 @ Georg Thieme Verlag KG Stuttgart · New York | ISSN 0016-5751

Correspondence

Dr. med Nina Combaz(-Söhnchen)

Abteilung Frau und Kind, Spital Sitten

Avenue du Grand-Champsec 80, 1951 Sitten, Schweiz

Dr.Combaz@cabinet-gynecologie.ch

Deutsche Version unter:

https://doi.org/10.1055/s-0043-119687

\section{ABSTRACT}

Mycoplasma species relevant to the urogenital tract include mycoplasma hominis, mycoplasma genitalia and ureaplasma urealyticum. Their occurrence in the context of urogynaecological disease has been demonstrated in urethritis, cystitis and upper renal tract infections. Their role in hyperactive bladder and interstitial cystitis/painful bladder syndrome is controversial. All the above-mentioned microorganisms can occur as commensals or as potential pathogens. In most cases their role in any particular pathology cannot be proven, only presumed. The aim of this systematic review was to summarise current knowledge on the influence of mycoplasma and ureaplasma in urogynaecological pathology and to provide clinical guidance on diagnosis (when and how is pathogen detection indicated?) and treatment. 377 relevant articles were analysed. In summary: a urethral swab for PCR analysis of the three bacteria should be performed in the context of symptomatic sterile leukocyturia, chronic urethritis and suspected hyperactive bladder or interstitial cystitis/painful bladder syndrome. Symptomatic women should be treated strictly according to results of the antibiogram.

\section{ZUSAMMENFASSUNG}

Die im Urogenitaltrakt relevanten Mykoplasmen sind Mycoplasma hominis, Mycoplasma genitalium und Ureaplasma urealyticum. Ihr Vorkommen wurde bei urogynäkologischen Krankheiten bereits bei der Urethritis, Zystitis und bei oberen Harnwegsinfekten erwiesen. Ihre Beteiligung an der Entstehung der hyperaktiven Blase sowie der interstitiellen Zystitis/ beim Bladder Pain Syndrome wird kontrovers diskutiert. Alle genannten Erreger können sowohl als einfache Kommensalen als auch als potenziell pathogene Keime vorkommen. In den meisten Fällen kann ihre Verantwortlichkeit für die jeweilige Pathologie nur vermutet und nicht bewiesen werden. Ziel dieses systematischen Reviews ist es, den aktuellen Wissensstand zum Einfluss von Mykoplasmen und Ureaplasmen auf urogynäkologische Pathologien bei Frauen zusammenzufassen und dem Kliniker Anhalt zu geben, wann und wie die Erregersuche indiziert ist und wie die Keime behandelt werden sollten. 377 gefundene Artikel wurden zu dieser Fragestellung analysiert. Fazit: Bei steriler symptomatischer Leukozyturie, chronischer Urethritis sowie bei Verdacht auf hyperaktive Blase oder interstitielle Zystitis/Bladder Pain Syndrome sollte ein Urethraabstrich mit PCR-Analyse auf die 3 Keime durchgeführt werden. Die Therapie sollte bei symptomatischen Frauen nur nach Antibiogramm erfolgen. 


\section{Introduction}

Mycoplasma and ureaplasma species, which are parasitic to humans, are the smallest known cell-wall-free intra- and extracellular bacteria belonging to the class Mollicutes. Their lack of a cell wall, extremely small genome and limited capacity for biosynthesis together explain their parasitic or saprophytic life style, their sensitivity to environmental factors, resistance to lactam antibiotics and high demands on living conditions.

These organisms can cause numerous often chronic conditions in humans. As parasites or commensals they receive essential metabolites such as fatty acids, amino acids, cholesterol and nucleic acid precursors from their host. Ureaplasma are defined and differentiated from mycoplasma species by their characteristic lysis of urea. Sixteen of the over 200 mycoplasma species known in the animal and plant kingdoms occur in the human body, however only six of these appear to be of pathological importance in immunocompetent human beings: mycoplasma pneumoniae, mycoplasma hominis, mycoplasma genitalium, mycoplasma fermentans, ureaplasma parvum und ureaplasma urealyticum [1]. Only mycoplasma hominis, mycoplasma genitalium and ureaplasma urealyticum are important pathogens in the human genital tract.

The prevalence of bacterial colonisation in women has been shown to correlate with number of sexual partners in previous months [2], and prevalence differs according to geographic and socio-economic circumstances. The pathogenic potential of these organisms is however not nearly as high as other sexually transmitted pathogens (especially chlamydia trachomatis).

Because of the close topographical relationship between the female urethra and genital tract it can be assumed that bacterial colonisation of the former from the latter can affect the urinary tract. A lot is already known about mycoplasma-associated genital tract infections, however there is still a lack of clarity on the influence and pathogenic potential of mycoplasma and ureaplasma species in the context of urinary tract infections and other urogynaecological symptoms such as irritable bladder and interstitial cystitis/bladder pain syndrome.

The aim of this review is to summarise current knowledge on the prevalence and effects of mycoplasma and ureaplasma infections, the best methods of pathogen detection and best treatment options for the associated urogynaecological conditions (upper and lower urinary tract infections, urethritis, overactive bladder $[\mathrm{OAB}]$, interstitial cystitis [IC]/the bladder pain syndrome [BPS] [3]). The results presented are intended to be a practical treatment aid for clinicians.

\section{Review}

\section{Literature search}

A systematic literature search was performed in the data banks PubMed and MEDLINE for publications between 1970 and 2017. Both "mycoplasma" and "ureaplasma" were used as search terms coupled with the following: "cystitis, bladder infection, urinary tract infection, LUTS, lower urinary tract, urethra, urethritis, pyelonephritis, upper urinary tract infection, immune deficiency, overactive bladder, hyperactive bladder, bladder irritation, inter- stitial cystitis, chronic pelvic pain, bladder pain, treatment, laboratory analyses, detection and analysis". For overall information on the topic a further search using the following terms was performed: "sexually transmitted diseases woman, reproductive tract, infertility, pregnancy, neonatal infection and delivery transmission". Both authors performed the research independently. Since very few publications were found on overactive bladder and interstitial cystitis/the bladder pain syndrome an additional search was conducted in the databases Scopus, Ovid and Science Direct. - Table 1 summarises the relevant literature found.

The initial literature analysis yielded 2055 articles. Together with the extended literature search a total of 2269 articles were identified. 54 publications were regarded by both authors as relevant and served as the basis for this review (• Fig. 1).

\section{Results}

The role of mycoplasma and ureaplasma in urinary tract infections

The persistence of irritable bladder symptoms following a urinary tract infection is a challenging situation for clinicians. Most uropathogenic organisms - especially those originating from faeces can be demonstrated on standard culture. Mycoplasma and ureaplasma species on the other hand are not. When these organisms are specifically sought they may be found in both asymptomatic [4] and symptomatic patients with sterile leukocyturia [5]. In women pathological significance is differentiated from harmless colonisation by the presence of clinical symptoms. This is complicated in addition by the fact that bacterial count in urine does not necessarily correlate with the amount of bacteria in the bladder wall. A significant number of these intracellular organisms may occur in the bladder wall in the absence of bacteriuria.

Mycoplasma hominis and ureaplasma urealyticum have also been demonstrated in patients with pyelonephritis [6]. The pathogens are thought to have reached the renal pelvis exclusively by ascending infection from the lower urinary tract. The detection of bacteria in catheter urine from the bladder does not therefore prove bacterial colonisation of the upper urinary tract [7].

We agree with the recommendation by Potts et al. that persistent lower urinary tract infection symptoms or pyelonephritis with negative standard cultures and nonresponse to routine antibiotics should prompt an active search for mycoplasma and ureaplasma, with treatment according to antibiogram if findings are positive. Pathogen detection should be undertaken before further expensive or invasive diagnostic measures are resorted to [8].

\section{Urethritis}

Urethritis due to mycoplasma and ureaplasma infection, so-called "nonchlamydial nongonococcal urethritis", is extensively described in men. There is however very little data on the topic in women: Moi et al., Falk et al. and Ross \& Jensen have all described urethritis in women caused by or associated with mycoplasma genitalium [9-11].

Although mycoplasma hominis and ureaplasma urealyticum have been found in women with urethritis [12], clear evidence of causative effect is still lacking. Kyndel et al. recently published a case-control study on the incidence of mycoplasma genitalium, ureaplasma urealyticum and ureaplasma parvum in patients with 
- Table 1 Search criteria coupled with the terms "mycoplasma" and "ureaplasma" and articles found. Results are shown for the systematic literature search in Pubmed and Medline using all relevant search criteria, and in Scopus, Ovid and Science Direct using search terms "overactive bladder, hyperactive bladder, bladder irritation, interstitial cystitis, chronic pelvic pain and bladder pain" with specification of subtopics.

\begin{tabular}{|l|r|}
\hline Search criteria & No. articles found \\
\hline Cystitis & 17 \\
\hline Bladder infection & 22 \\
\hline Urinary tract infection & 100 \\
\hline LUTS & 7 \\
\hline Lower urinary tract & 22 \\
\hline Urethra & 106 \\
\hline Urethritis & 266 \\
\hline Pyelonephritis & 14 \\
\hline Upper urinary tract infection & 2 \\
\hline Immune deficiency & 52 \\
\hline Overactive bladder & 8 \\
\hline Hyperactive bladder & 3 \\
\hline Bladder irritation & 6 \\
\hline Interstitial cystitis & 66 \\
\hline Chronic pelvic pain & 116 \\
\hline Bladder pain & 25 \\
\hline Treatment & 483 \\
\hline Laboratory analysis & 8 \\
\hline Detection and analysis & 7 \\
\hline Sexually transmitted diseases woman & 134 \\
\hline Reproduction tract & 91 \\
\hline Infertility & 178 \\
\hline Pregnancy & 403 \\
\hline Neonate infection & 123 \\
\hline Delivery transmission & 10 \\
\hline
\end{tabular}

chronic urethral pain. In contrast to Stamm et al. [13], the authors found no difference between affected patients and the control group [14].

In summary, data on this topic in women is sketchy. In the context of chronic urethral symptoms with negative routine cultures we recommend a urethral swab with PCR analysis for the three relevant mollicutes, and in case of positive findings appropriate treatment according to resistogram.

\section{Can mycoplasma and ureaplasma cause overactive bladder or interstitial cystitis?}

The International Continence Society (ICS) defines OAB as urinary urgency with or without urgency urinary incontinence in association with urinary frequency and/or nocturia [15]. The symptoms thus match those of simple cystitis.

Interstitial cystitis - recently renamed the Bladder Pain Syndrome [3] - is defined by "chronic lower abdominal pain (continuous for at least six months) with discomfort or pressure related

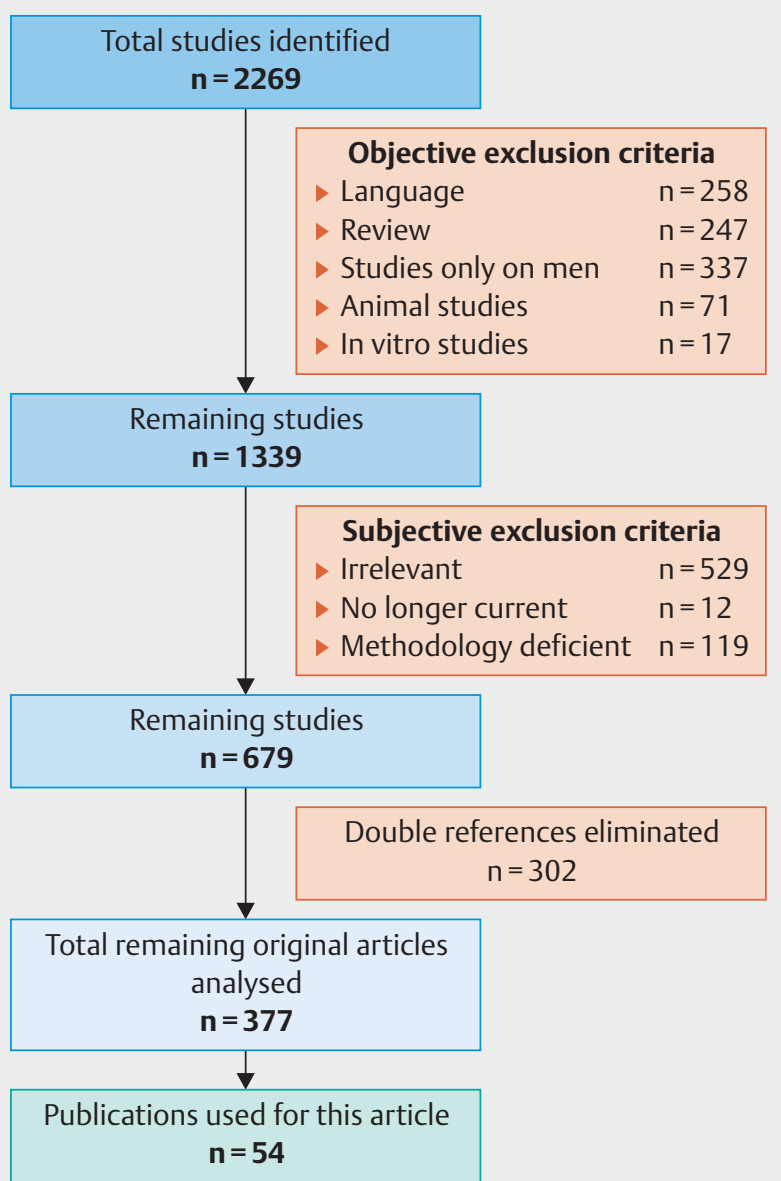

- Fig. 1 Literature search flow diagram. The initial 2269 identified articles were analysed. Original publications in German, English and French were included. Using objective and subjective selection criteria all review articles, studies conducted only on men or animals and in vitro studies were excluded from the analysis. Double references and studies regarded as irrelevant were also eliminated. 377 articles remained for final analysis. 54 of these publications were regarded as currently relevant and served as the basis for this article.

to the bladder. In addition at least one further symptom is present such as persistent urinary urgency or frequency" [15].

There is therefore overlap between the symptoms of OAB and BPS. OAB is more common around menopause whereas BPS mostly affects premenopausal women. Both OAB [16] and BPS [17] occur more commonly in women than men. The diagnoses $O A B$ and IC/BPS can only be made after exclusion of possible infectious and other pathologies. The aetiology of OAB is mostly, and that of BPS currently still always fully unexplained [18].

The theory that initial injury to the urothelium through acute or chronic infection, causing persistent irritation of the bladder wall and subsequently OAB and IC/BPS, has not been proven. Neither a particular microorganism nor any specific spectrum of pathogens has been shown to be related to the two conditions.

In the late 1990s, using the laboratory methods of the day various investigators attempted to ascribe an infectious aetiology to 
interstitial cystitis - without success $[19,20]$. Despite controversial results [21] numerous studies however showed positive outcomes with empiric antibiotic treatment (doxycycline) for $O A B$ and IC/BPS [22-25]. The question still remains whether OAB/IC/ BPS can in fact be defined as idiopathic. Chronic infection with one or more as yet undetected pathogens seems more likely. Since mycoplasma and ureaplasma species are often eradicated by doxycycline and are better detected with newer diagnostic methods, the question must be asked once again whether the findings from the 1990s are still valid today, and whether there is in fact a link between OAB/BPS and mollicutes.

Numerous recent studies have shown that ureaplasma and mycoplasma species can be detected in the urine of women with OAB $[26,27]$ or IC [25]. Potts et al. showed that symptoms improved in patients with IC following targeted antibiotic treatment [25]. A thorough search through the current available literature however brings us to the conclusion that there is far too little data to provide an evidence-based answer to this question. We therefore agree with the recommendation that all patients with chronic unexplained urinary tract symptoms should be tested for mollicutes (mycoplasma and ureaplasma) before invasive diagnostic measures and long-term treatments. Patients with positive bacterial testing should be treated accordingly.

\section{What are the best detection methods for mycoplasma and ureaplasma?}

Mycoplasma genitalium is not detected on routine culture due to extremely slow growth. Real-time polymerase chain reaction $(P C R)$ is the diagnostic method of choice. In contrast, ureaplasma urealyticum and mycoplasma hominis can be identified on culture or PCR [28].

It is important for the clinician to know that correct sampling technique from the appropriate site is at least as important for organism detection as the choice of laboratory method [29]! Humburg et al. found that detection rates of mycoplasma and ureaplasma in women with urinary tract symptoms were higher using urethral swabs than early morning urine cultures or vaginal swabs [30], however in the presence of vaginal itch vaginal swabs provided the best results [31]. Freezing of PCR specimens appears to reduce bacterial detection [32].

\section{Treatment of infections}

The most difficult question is left to the clinician, who must decide whether a given bacterium, proven on laboratory tests, is pathogenically significant or not.

Ureaplasma and mycoplasma species do not have a cell wall. Beta-lactam antibiotics and vancomycin are thus ineffective. Cyclines (doxycycline, monocycline), josamycin and the fluoroquinolones are effective against the three species known to be pathogenic in the urogenital tract. Tetracyclines and the fluoroquinolones are the first choice antibiotics. In pregnant women in whom these drugs are contraindicated macrolides such as erythromycin are often used.

In addition to the naturally occurring resistances there is increasing acquired antibiotic resistance so that if possible treatment should only begin once the results of antibiotic resistance testing are available.
Current treatment options include:

- azithromycin $1 \mathrm{~g}$ as a single dose

- azithromycin 1,5 g total dose given over 5 days

- or doxycycline $100 \mathrm{mg} 2 \times$ daily for 7 days.

Treatment success should be tested three weeks after treatment at the earliest, especially in the case of mycoplasma genitalium. In the presence of bacterial persistence common antibiotic regimes are

- metronidazole $500 \mathrm{mg} 2 \times /$ day for 5-7 days plus azithromycin for 5 days

- or doxycycline for 7 days

- or moxifloxacin $400 \mathrm{mg}$ per os $1 \times /$ day for 7-14 days [33].

Moxifloxacin should be used with caution and only in the context of treatment failure since it can cause a rare but severe liver reaction. Mycoplasma genitalium infection acquired in Southeast Asia is resistant to macrolides and quinolones in $10 \%$ of cases and pristinamycin is the only effective antibiotic in these patients [34].

Treatment of the patient's partner with the same antibiotic shown to be effective in the index patient is generally recommended. Condom use or abstinence from sexual intercourse is recommended until symptoms have resolved.

\section{Outlook for the future}

New laboratory methods and gene analyses provide promise for the future: it has recently become possible to determine the female microbiome in catheter urine using culture and 16S RNA sequencing. This has already led to the finding that urine of symptom-free patients contains bacteria and is not sterile as previously assumed $[35,36]$. Urine appears to constitute its own microbiological niche that is extremely diverse and may include typical uropathogens such as mycoplasma and ureaplasma species [26, 36].

\section{Limitations of this review}

There is little factual knowledge regarding women in this field. Studies on men, which are far more numerous, were deliberately excluded from this analysis in order to focus and provide clarity on the evidence in women. Preclinical studies would expand on these findings.

The heterogeneity of definitions e.g. interstitial cystitis, the painful bladder syndrome and $O A B$ is a further limitation since they were not used according to the international criteria of the IUGA or ICS in all articles and are thus of limited informative value. Larger, high evidence level, randomised studies of treatment are lacking.

\section{Conclusion}

Our knowledge about mycoplasma and ureaplasma species in the urogenital tract is incomplete. There is very little literature on this topic in women. Further studies especially in women are urgently needed. In view of the current data situation these pathogens, which are difficult to culture, should be actively sought by urethral swab for PCR analysis in patients with recurrent infections or when standard microbiological cultures/swabs are negative. Treatment of symptomatic women should always be guided by antibiotic resistance testing. It can be presumed that the role of these pathogens in women with chronic urinary tract symptoms has been 
underestimated as they are difficult to detect and their intracellular nature makes conventional antibiotics ineffective.

\section{Acknowledgements}

We thank Dr. Etienne Combaz for his all-encompassing support and technical help in the preparation of this review.

\section{Conflict of Interest}

N. Combaz and A. Kuhn declare that no competing interests exist. This article does not refer to any studies by the authors on people or animals.

\section{References}

[1] Waites KB, Xiao L, Paralanov V et al. Molecular methods for the detection of mycoplasma and ureaplasma infections in humans: a paper from the 2011 William Beaumont Hospital Symposium on molecular pathology. J Mol Diagn 2012; 14: 437-450

[2] Jensen AJ, Kleveland CR, Moghaddam A et al. Chlamydia trachomatis, Mycoplasma genitalium and Ureaplasma urealyticum among students in northern Norway. J Eur Acad Dermatol Venereol 2013; 27: e91-e96

[3] van de Merwe JP, Nordling J, Bouchelouche P et al. Diagnostic criteria, classification, and nomenclature for painful bladder syndrome/interstitial cystitis: an ESSIC proposal. Eur Urol 2008; 53: 60-67

[4] Jensen JS. Mycoplasma genitalium: the aetiological agent of urethritis and other sexually transmitted diseases. J Eur Acad Dermatol Venereol 2004; 18: 1-11

[5] Nassar FA, Abu-Elamreen FH, Shubair ME et al. Detection of Chlamydia trachomatis and Mycoplasma hominis, genitalium and Ureaplasma urealyticum by polymerase chain reaction in patients with sterile pyuria. Adv Med Sci 2008; 53: 80-86

[6] Thomsen AC. The occurrence of mycoplasmas in the urinary tract of patients with chronic pyelonephritis. Acta Pathol Microbiol Scand B 1975; 83: $10-16$

[7] Thomsen AC. Occurrence of mycoplasmas in urinary tracts of patients with acute pyelonephritis. J Clin Microbiol 1978; 8: 84-88

[8] Potts JM, Ward AM, Rackley RR. Association of chronic urinary symptoms in women and Ureaplasma urealyticum. Urology 2000; 55: 486-489

[9] Moi H, Reinton N, Randjelovic I et al. Urethral inflammatory response to ureaplasma is significantly lower than to Mycoplasma genitalium and Chlamydia trachomatis. Int J STD AIDS 2017; 28: 773-780. doi:10.1177/0956462416666482

[10] Falk L, Fredlund H, Jensen JS. Signs and symptoms of urethritis and cervicitis among women with or without Mycoplasma genitalium or Chlamydia trachomatis infection. Sex Transm Infect 2005; 81: 73-78

[11] Ross JDC, Jensen JS. Mycoplasma genitalium as a sexually transmitted infection: implications for screening, testing, and treatment. Sex Transm Infect 2006; 82: 269-271

[12] Bump RC, Copeland WE. Urethral isolation of the genital mycoplasmas and Chlamydia trachomatis in women with chronic urologic complaints. Am J Obstet Gynecol 1985; 152: 38-41

[13] Stamm WE, Running K, Hale J et al. Etiologic role of Mycoplasma hominis and Ureaplasma urealyticum in women with the acute urethral syndrome. Sex Transm Dis 1983; 10: 318-322

[14] Kyndel A, Elmér C, Källman O et al. Mycoplasmataceae colonizations in women with urethral pain syndrome: a case-control study. J Low Genit Tract Dis 2016; 20: 272-274

[15] Abrams P, Cardozo L, Fall M et al. The standardisation of terminology in lower urinary tract function: report from the standardisation sub-committee of the International Continence Society. Urology 2003; 61: 37-49
[16] Eapen RS, Radomski SB. Review of the epidemiology of overactive bladder. Res Rep Urol 2016; 8: 71-76

[17] Payne CK, Joyce GF, Wise M et al. Interstitial cystitis and painful bladder syndrome. J Urol 2007; 177: 2042-2049

[18] Vella M, Robinson D, Cardozo L. Painful bladder syndrome. Obstet Gynaecol Reprod Med 2012; 22: 44-49

[19] Keay S, Schwalbe RS, Trifillis AL et al. A prospective study of microorganisms in urine and bladder biopsies from interstitial cystitis patients and controls. Urology 1995; 45: 223-229

[20] Duncan JL, Schaeffer AJ. Do infectious agents cause interstitial cystitis? Urology 1997; 49: 48-51

[21] Warren JW, Horne LM, Hebel JR et al. Pilot study of sequential oral antibiotics for the treatment of interstitial cystitis. J Urol 2000; 163: 16851688

[22] Dutkiewicz S. Treatment efficacy of chronic urethral syndrome with Doxycycline in females. Cent Eur J Urol 2010; 63: 82-83

[23] Warren JW, Horne LM, Hebel JR et al. Pilot study of sequential oral antibiotics for the treatment of interstitial cystitis. J Urol 2000; 163: 16851688

[24] Burkhard FC, Blick N, Hochreiter WW et al. Urinary urgency and frequency, and chronic urethral and/or pelvic pain in females. Can doxycycline help? J Urol 2004; 172: 232-235

[25] Potts JM, Ward AM, Rackley RR. Association of chronic urinary symptoms in women and Ureaplasma urealyticum. Urology 2000; 55: 486-489

[26] Siddiqui $H$, Lagesen $K$, Nederbragt $A$ J et al. Pathogens in urine from a female patient with overactive bladder syndrome detected by culture-independent high throughput sequencing: a case report. Open Microbiol J 2014; 8: 148-153

[27] Lee YS, Kim JY, Kim JC et al. Prevalence and treatment efficacy of genitourinary mycoplasmas in women with overactive bladder symptoms. Korean J Urol 2010; 51: 625-630

[28] Garner CM, Hubbold LM, Chakraborti PR. Mycoplasma detection in cel cultures: a comparison of four methods. Br ] Biomed Sci 2000; 57: 295301

[29] Moi H, Reinton N, Moghaddam A. Mycoplasma genitalium in women with lower genital tract inflammation. Sex Transm Infect 2009; 85: 10-14

[30] Humburg J, Frei R, Wight E et al. Accuracy of urethral swab and urine analysis for the detection of Mycoplasma hominis and Ureaplasma urealyticum in women with lower urinary tract symptoms. Arch Gynecol Obstet 2012; 285: 1049-1053

[31] Casin I, Vexiau-Robert D, De La Salmonière P et al. High prevalence of Mycoplasma genitalium in the lower genitourinary tract of women attending a sexually transmitted disease clinic in Paris, France. Sex Transm Dis 2002; 29: 353-359

[32] Carlsen KH, Jensen JS. Mycoplasma genitalium PCR: does freezing of specimens affect sensitivity? J Clin Microbiol 2010; 48: 3624-3627

[33] Bébéar CM, de Barbeyrac B, Pereyre $S$ et al. Activity of moxifloxacin against the urogenital mycoplasmas Ureaplasma spp., Mycoplasma hominis and Mycoplasma genitalium and Chlamydia trachomatis. Clin Microbiol Infect Off Publ Eur Soc Clin Microbiol Infect Dis 2008; 14: 801-805

[34] Bissessor M, Tabrizi SN, Twin J et al. Macrolide resistance and azithromycin failure in a Mycoplasma genitalium-infected cohort and response of azithromycin failures to alternative antibiotic regimens. Clin Infect Dis Off Publ Infect Dis Soc Am 2015; 60: 1228-1236

[35] Hilt EE, McKinley K, Pearce MM et al. Urine is not sterile: use of enhanced urine culture techniques to detect resident bacterial flora in the adult female bladder. J Clin Microbiol 2014; 52: 871-876

[36] Wolfe A], Toh E, Shibata $\mathrm{N}$ et al. Evidence of uncultivated bacteria in the adult female bladder. J Clin Microbiol 2012; 50: 1376-1383

Further literature is available from the corresponding author on request. 